\title{
Low Temperature Combustion Processed Stable Al Doped ZnO Thin Film Transistor: Process Extendable up to Flexible Devices
}

\author{
Venkateshwarlu Sarangi ${ }^{1 *}$, Srinivas Gandla ${ }^{2}$ \\ ${ }^{1}$ Department of Electronic Engineering, City University of Hong Kong, Hong Kong \\ ${ }^{2}$ Department of Metallurgical Engineering and Materials Science, \\ Indian Institute of Technology Bombay (IITB), Mumbai, India
}

* Corresponding author email: venky.sarangi@gmail.com

Received: 16 April 2016 / Revised: 01 December 2016/ Accepted: 07 December 2016 / Published: 11 December 2016

\begin{abstract}
We report combustion synthesis of polycrystalline Aluminium doped zinc oxide (AZO) at low temperature for next generation low cost, flexible thin film transistor (TFT) application. Solution processed AZO thin film has been characterized by $\mathrm{X}$ ray diffraction and atomic force microscopy to confirm crystallinity. In this research work TFT with solution processed AZO as channel layer has been fabricated on both rigid and flexible substrate which exhibits excellent electrical stability and improved field effect mobility of $1.2 \mathrm{~cm}^{2} \mathrm{~V}^{-1} \mathrm{~S}^{-1}$, threshold voltage of $15 \mathrm{~V}$ and on-off ratio of $10^{6}$ as compared to pure $\mathrm{ZnO}$ based TFT. All the measurements have been carried out with varying $\mathrm{Al}$ concentration. Moreover, variation in defect density of AZO with $\mathrm{Al}$ concentration which essentially causes significant change in TFT's performance is demonstrated by chemical composition and bonding state analysis using XPS. Our results suggest that low temperature solution processed AZO TFTs have a potential for low cost, flexible and transparent electronic applications.
\end{abstract}

Keywords: Aluminium, ZnO, Combustion synthesis, Doping, Flexible Films, Thin Film Transistor (TFT), Low temperature, Spin Coating, XRD, SEM, AFM, XPS.

\section{Introduction}

In last few years, research on thin film transistor (TFT) is majorly focused to use transparent oxide semiconductor as channel material for future transparent display technology [1]. Zinc oxide $(\mathrm{ZnO})$ is one of such semiconductor [2] and especially because of nontoxicity [3], reasonably good crystallinity [4], high electron mobility [5] and light weight [6], they are widely used for channel material in TFTs [7]. Recently several metals like In, Sn, Ga [8] have been successfully doped into pure $\mathrm{ZnO}$ and subsequently IZO [9] (In doped $\mathrm{ZnO}$ ), ZTO (Sn doped $\mathrm{ZnO}$ ) [7], IGZO (In,Ga doped $\mathrm{ZnO}$ ) [10] have been employed as channel material in order to further improve device performance [9], [11], [12], [13]. But most of those dopants are either expensive or need process conditions such as higher temperature $\left(>300{ }^{\circ} \mathrm{C}\right)$, high vacuum for thin film formation which do not allow them in low cost flexible electronic applications [14]. It is because of the fact that most of the flexible substrates such as PET [15] and PEN [16] have very low glass transition temperature $\left(\mathrm{T}_{\mathrm{g}}\right)(<200$ $\left.{ }^{\circ} \mathrm{C}\right)$. So in recent days the main challenge is to find suitable channel material and develop a low temperature device fabrication method which is appropriate for next generation low cost flexible electronics. In view of this, we choose $\mathrm{Al}$ doped $\mathrm{ZnO}(\mathrm{AZO})$ as channel material because $\mathrm{Al}$ is inexpensive and harmless to human. Recently, in few reports RF sputtered AZO [17] and PECVD deposited AZO [18] have been employed as channel layer and TFT characteristics have been subsequently investigated. But by now no work has been reported on low temperature solution process of AZO thin film.

In this article, we report combustion synthesis of $\mathrm{Al}$ doped $\mathrm{ZnO}$, which allows the formation of 
Low Temperature Combustion Processed Stable Al Doped ZnO Thin Film Transistor: Process Extendable up to Flexible Devices

thin film of $\mathrm{AZO}$ on $\mathrm{Si} / \mathrm{SiO}_{2}$ substrate by solution spin coating and subsequent annealing at temperature down to $250^{\circ} \mathrm{C}$. Pure $\mathrm{ZnO}$ thin film was also prepared in similar manner for comparing performance of fabricated TFT devices. In typical experiment acetylacetone has been used here as combustion agent or fuel which provides self-generated energy to drive the reactions at low temperature [13], [11]. While fabrication we have followed staggered (top contact bottom gate) architecture and fabricated TFTs on both rigid Si and flexible PET substrate. We have got maximum field effect mobility 1.2 $\mathrm{cm}^{2} \mathrm{~V}^{-1} \mathrm{~S}^{-1}$ for $3 \mathrm{~mol} \%$ AZO which is far better than that $\left(0.8 \mathrm{~cm}^{2} \mathrm{~V}^{-1} \mathrm{~S}^{-1}\right)$ of pure $\mathrm{ZnO}$ based TFT. Moreover, we have tried to explain the mobility variation with $3 \mathrm{M}, 5 \mathrm{M}, 7 \mathrm{M}$ and $9 \mathrm{M}$ of AZO TFT. Further we have tried to explain the mobility variation with $3 \mathrm{M}, 5 \mathrm{M}, 7 \mathrm{M}$ and $9 \mathrm{M}$ of $\mathrm{AZO}$ with the help of defect state analysis done by XPS measurement. Then bias stress measurement was also done to show electrical stability of the devices. So overall better performing TFTs were obtained using low temperature solution processed AZO as channel material as compared to pure $\mathrm{ZnO}$.

\section{Materials and Methods}

All the chemicals were purchased from Sigma Aldrich and used without further purification. Firstly, zinc nitrate hexa-hydrate $\left(\mathrm{Zn}\left(\mathrm{HNO}_{3}\right)_{2} .6 \mathrm{H}_{2} \mathrm{O}\right)$ and acetylacetone $\left(\mathrm{C}_{5} \mathrm{H}_{8} \mathrm{O}_{2}\right)$ were dissolved in $5 \mathrm{ml}$ of 2-methoxyethonol $\left(\mathrm{C}_{6} \mathrm{H}_{14} \mathrm{O}_{3}\right)$ to obtain 0.05 molar (M) solution. Further, Aluminium nitrate nona-hydrate $\left(\mathrm{Al}\left(\mathrm{NO}_{3}\right)_{3} .9 \mathrm{H}_{2} \mathrm{O}\right)$ and acetylacetone $\left(\mathrm{C}_{5} \mathrm{H}_{8} \mathrm{O}_{2}\right)$ were dissolved in 2-methoxyethonol to obtain 0.005M solution. Zinc nitrate hexa-hydrate and Aluminium nitrate nona-hydrate solutions were aged for $12 \mathrm{hr}$ for completely dissolving metal nitrate salt in respective solvent. Combustion precursor solutions were amalgamated with variation in molar percentage $3 \%, 5 \%, 7 \%$, and $9 \%$ ) of $\mathrm{Al}\left(\mathrm{NO}_{3}\right)_{3} .9 \mathrm{H}_{2} \mathrm{O}$ solution to obtain $\mathrm{AZO}$ with variable $\mathrm{Al}$ mole. $\%$. precursors with $(3 \%$, $5 \%, 7 \%$ and $9 \%$ ). Finally, pure $\mathrm{ZnO}$ and different molar concentrations of AZO solutions were heated to $60^{\circ} \mathrm{C}$ with magnetic stirring for $1 \mathrm{hr}$ on a hot plate before film casting.

\section{Device Fabrication}

TFTs with top contact bottom gate structure were fabricated on both rigid $(\mathrm{n}++\mathrm{Si}$ with resistivity $<0.001-0.005 \mathrm{ohm} \mathrm{cm}$ ) and flexible (ITO coated PET sheet) substrate. Thermally grown $\mathrm{SiO}_{2}$ and sputtered $\mathrm{SiO}_{2}$ were used as dielectric on Si wafer and ITO coated PET sheet respectively. Then, on the top of this $\mathrm{SiO}_{2} / \mathrm{Si}$ grown layer, pure $\mathrm{ZnO}$ and $\mathrm{AZO}$ combustion precursors were spin coated (Model No: SPIN NXG-P1) on $\mathrm{SiO}_{2} / \mathrm{Si}$ substrate at $3000 \mathrm{rpm}$ for 30 secs in ambiance. The films were pre-heated at $150{ }^{\circ} \mathrm{C}$ for 5 mins to evaporate residual solvent and this process was repeated until the desired thickness was obtained. Finally, the samples were annealed at $250{ }^{\circ} \mathrm{C}$ for 1 hour for different concentration of the thin films. The annealing temperature is kept as 1 hour and then slowly decreased to the room temperature in ambient environment. Finally, $\mathrm{Al}$ source and drain contacts with channel length (L) of $100 \mu \mathrm{m}$ and width of $600 \mu \mathrm{m}$ were thermally evaporated using shadow mask.

\section{Results and Discussion}

\subsection{XRD Analysis}

Crystal structure was examined by X-ray diffractometry (Philips PW 3040/60) with Cu K $\alpha$ radiation $(\lambda=1.5418 \AA)$. We have observed the peaks corresponding to (100), (002) and (101) planes, which shows that the AZO film is polycrystalline as shown in Figure 1.

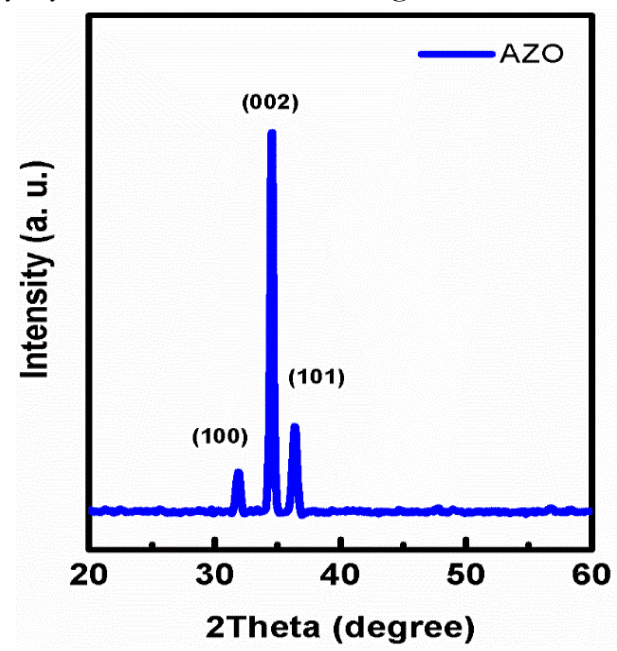

Figure 1: XRD pattern of AZO thin film deposited by spin coating technique, preheating at $150^{\circ} \mathrm{C}$ and annealed at $250^{\circ} \mathrm{C}$ and FEG-SEM image of AZO thin film. 
Sarangi et al., J. Mod. Mater.; Vol. 3, Issue 1, pp: 14-23, 2017

The unit cell has hexagonal crystal structure with lattice parameters are $\mathrm{a}=\mathrm{b}=3.2498 \AA, \mathrm{c}=5.2066$ $\AA, \alpha=\beta=90^{\circ}, \gamma=120^{\circ}$. Obtained peaks are compared with standard XRD pattern (JCPDS: 00-036-1451) and are normalized. It was identified that $\mathrm{ZnO}$ film was formed a hexagonal wurtzite structure and a preferred orientation with the c-axis perpendicular to the substrate and the particle size was calculated from the Scherrer formula as shown in equation 1 .

$$
\mathrm{D}=\mathrm{K} \lambda /(\mathrm{B} \cos \theta)
$$

In which the average $\mathrm{D}$ is the grain size and $\lambda$ is the wavelength of the incident $\mathrm{x}$-ray, $\mathrm{K}$ is a numerical constant $\sim 0.96, \theta$ is the Bragg angle, and $\mathrm{B}$ is the full-width half maximum, the estimated average grain size is around $\sim 15 \mathrm{~nm}$. XRD patterns of AZO thin films annealed at 250 ${ }^{\circ} \mathrm{C}$ and FEG-SEM image of AZO thin film is shown in Figure 2. Thermogravimetric analysis (TGA) data is plotted for various precursors such as $\mathrm{AZO}$ and $\mathrm{ZnO}$ by using combustion method that to observed the variation of mass loss in both $\mathrm{AZO}$ and $\mathrm{ZnO}$ precursors are shown in Figure 3.

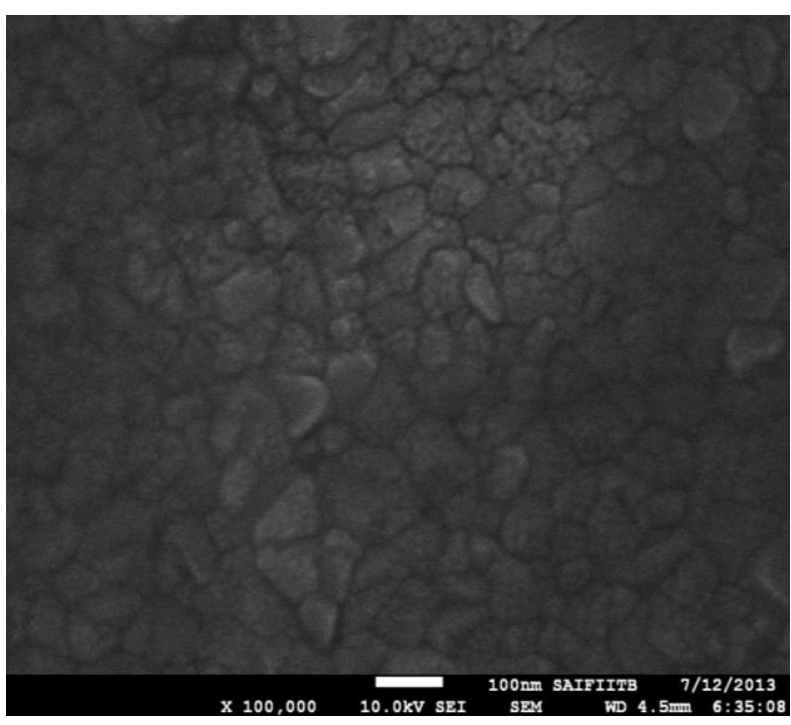

Figure 2: FEG-SEM image of AZO thin film deposited by spin coating technique, preheating at $150^{\circ} \mathrm{C}$ and annealed at $250^{\circ} \mathrm{C}$.

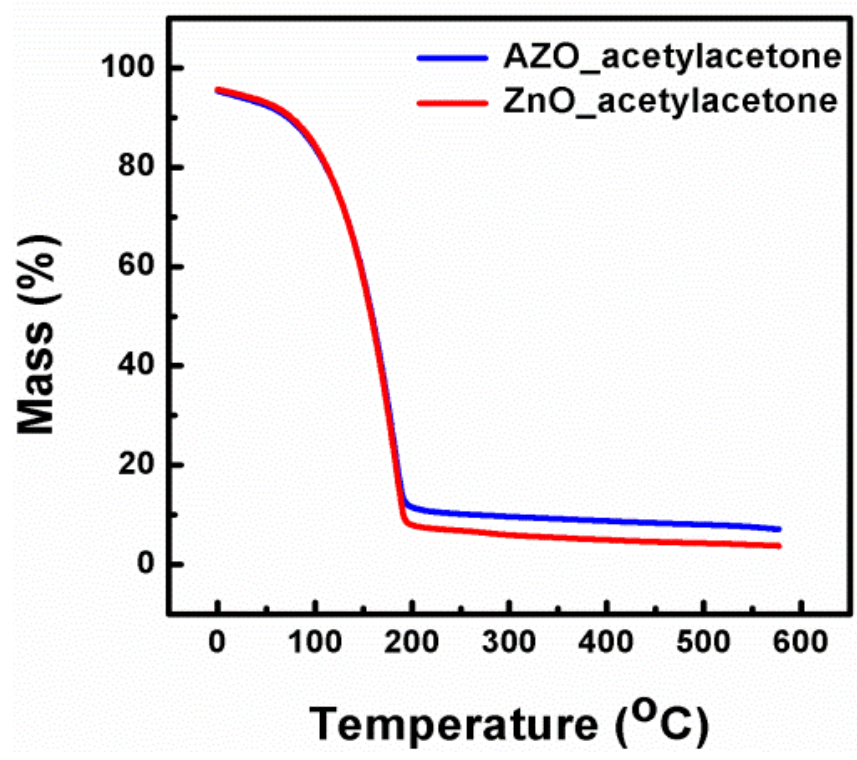

Figure 3: TGA analysis of AZO combustion and $\mathrm{ZnO}$ precursor solutions.

\subsection{AFM Analysis}

Atomic Force microscope (AFM : model MMAFMLN-AM-1897) used to measure the topography of the AZO thin films. The slightly rougher and porous surface is a common nature of solution processed AZO thin films. From AFM characterization of AZO Thin films with various molar concentration such as $3 \mathrm{M}, 5 \mathrm{M}, 7$ $\mathrm{M}$ and $9 \mathrm{M}$ and it is noticed that surface roughness and grain size are decreased while increased the molar concentration of $\mathrm{AZO}$ at annealing temperature from $250{ }^{\circ} \mathrm{C}$. It indicated that there would be more defects existing at low concentration of the AZO films with varying grain size and orientation distributions. We can see the surface roughness of the $\mathrm{ZnO}$ thin films in Figure 4 in 2D images. 
Low Temperature Combustion Processed Stable Al Doped ZnO Thin Film Transistor: Process Extendable up to Flexible Devices
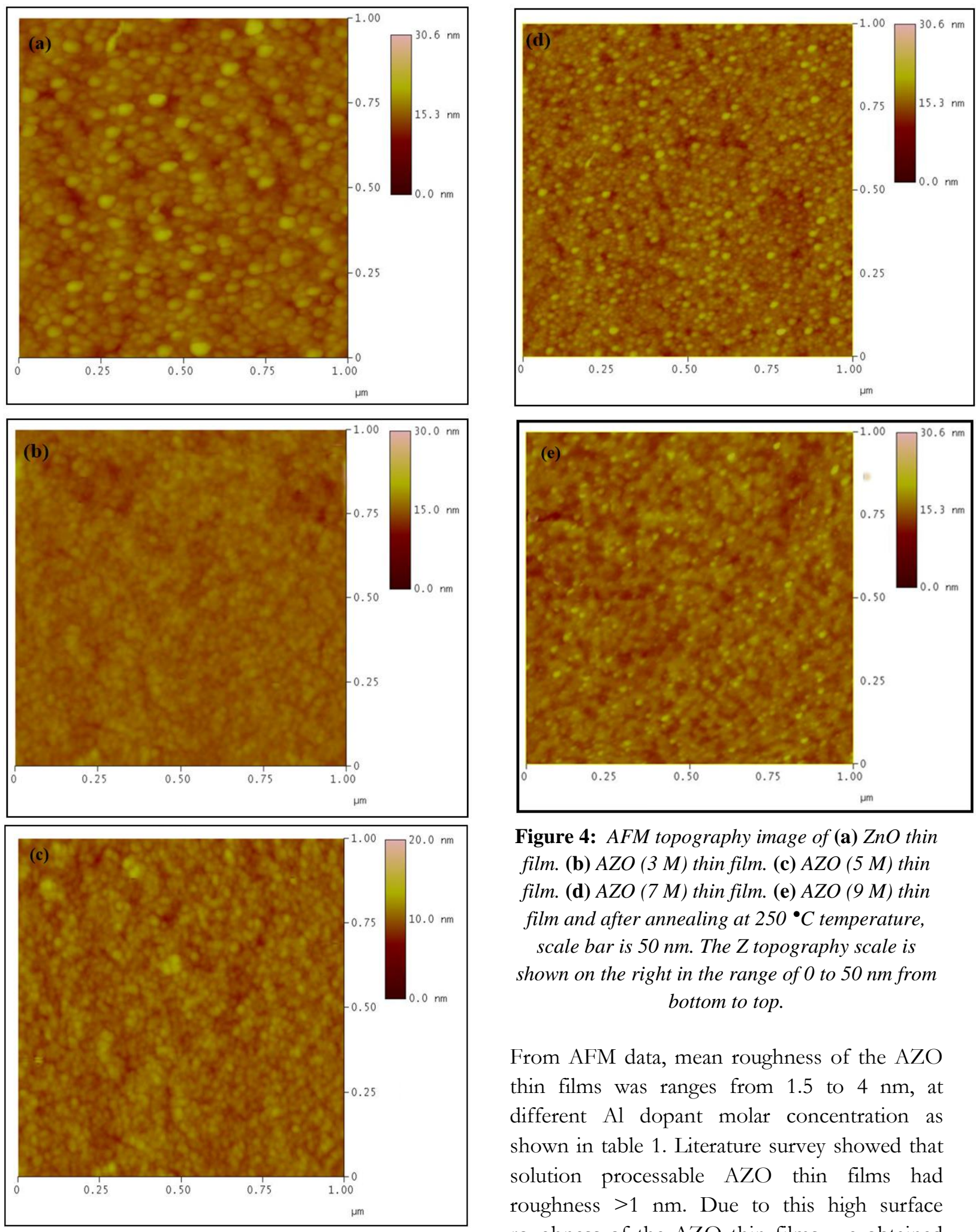

Figure 4: AFM topography image of (a) ZnO thin film. (b) $A Z O(3 \mathrm{M})$ thin film. (c) AZO (5 M) thin film. (d) $A Z O(7 M)$ thin film. (e) $A Z O(9 M)$ thin film and after annealing at $250{ }^{\circ} \mathrm{C}$ temperature, scale bar is $50 \mathrm{~nm}$. The $Z$ topography scale is shown on the right in the range of 0 to $50 \mathrm{~nm}$ from bottom to top.

From AFM data, mean roughness of the AZO thin films was ranges from 1.5 to $4 \mathrm{~nm}$, at different $\mathrm{Al}$ dopant molar concentration as shown in table 1. Literature survey showed that solution processable AZO thin films had roughness $>1 \mathrm{~nm}$. Due to this high surface roughness of the AZO thin films, we obtained low mobility of AZO TFT at high $\mathrm{Al}$ concentration. AZO thin films surface roughness was increased with respect to decreasing of $\mathrm{Al}$ concentration. Thin film surface roughness can be effect on device performance and lower roughness of thin film provide the better properties of device output. The values of mean 
roughness at various concentration $\mathrm{Al}$ of the AZO thin films were shown in Table 1.

Table 1: Surface roughness for AZO thin films of different Al dopant molar concentrations

\begin{tabular}{|c|c|c|}
\hline Material & $\begin{array}{c}\text { Molar } \\
\text { concentration }\end{array}$ & $\begin{array}{c}\text { Mean } \\
\text { roughness } \\
\text { (nm) }\end{array}$ \\
\hline ZnO thin film & 0 & 4 \\
\hline AZO thin film & 3 & 3.7 \\
\hline AZO thin film & 5 & 1.8 \\
\hline AZO thin film & 7 & 1.5 \\
\hline AZO thin film & 9 & 1 \\
\hline
\end{tabular}

\subsection{XPS Analysis}

X-ray photoelectron spectroscopy (XPS) was used to analyse AZO surface impurities, carbon contamination, and oxygen binding as shown in Figures 5 below.

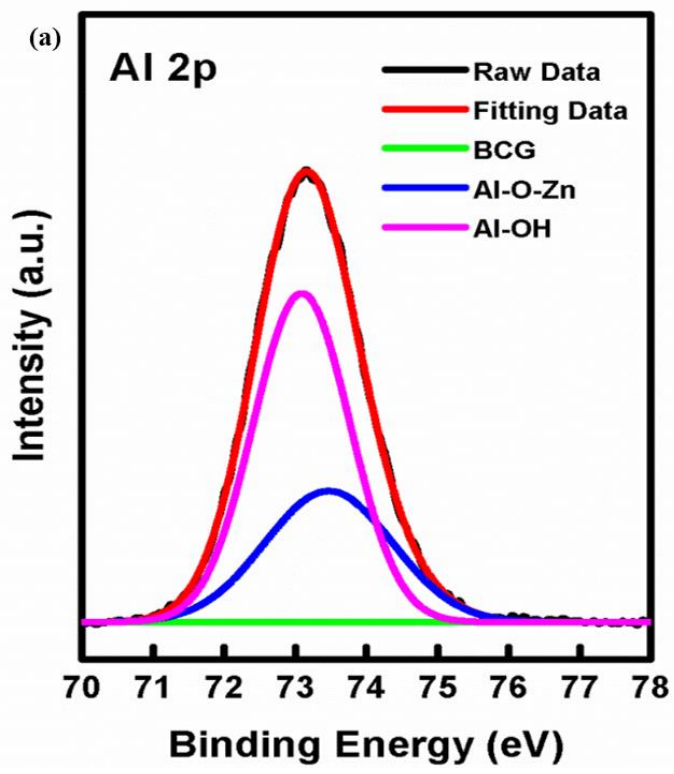

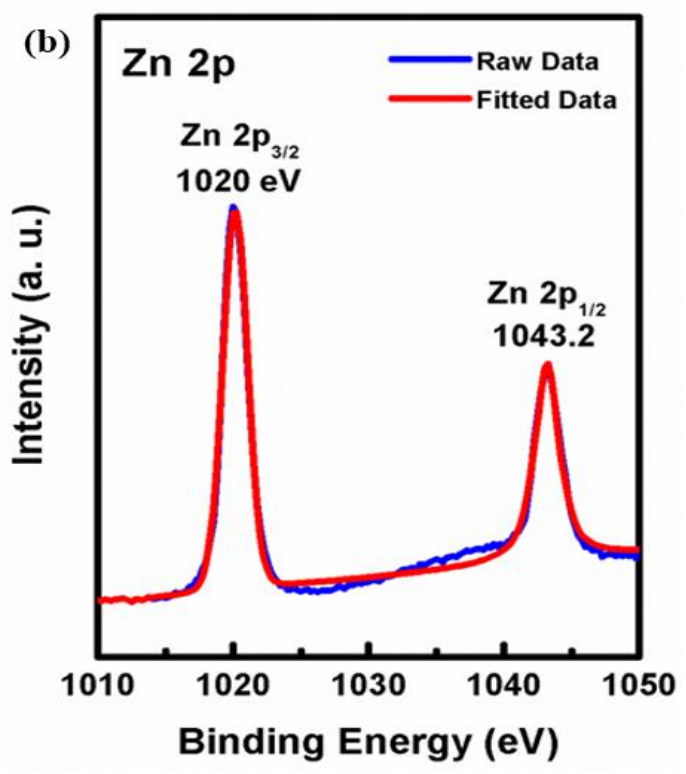
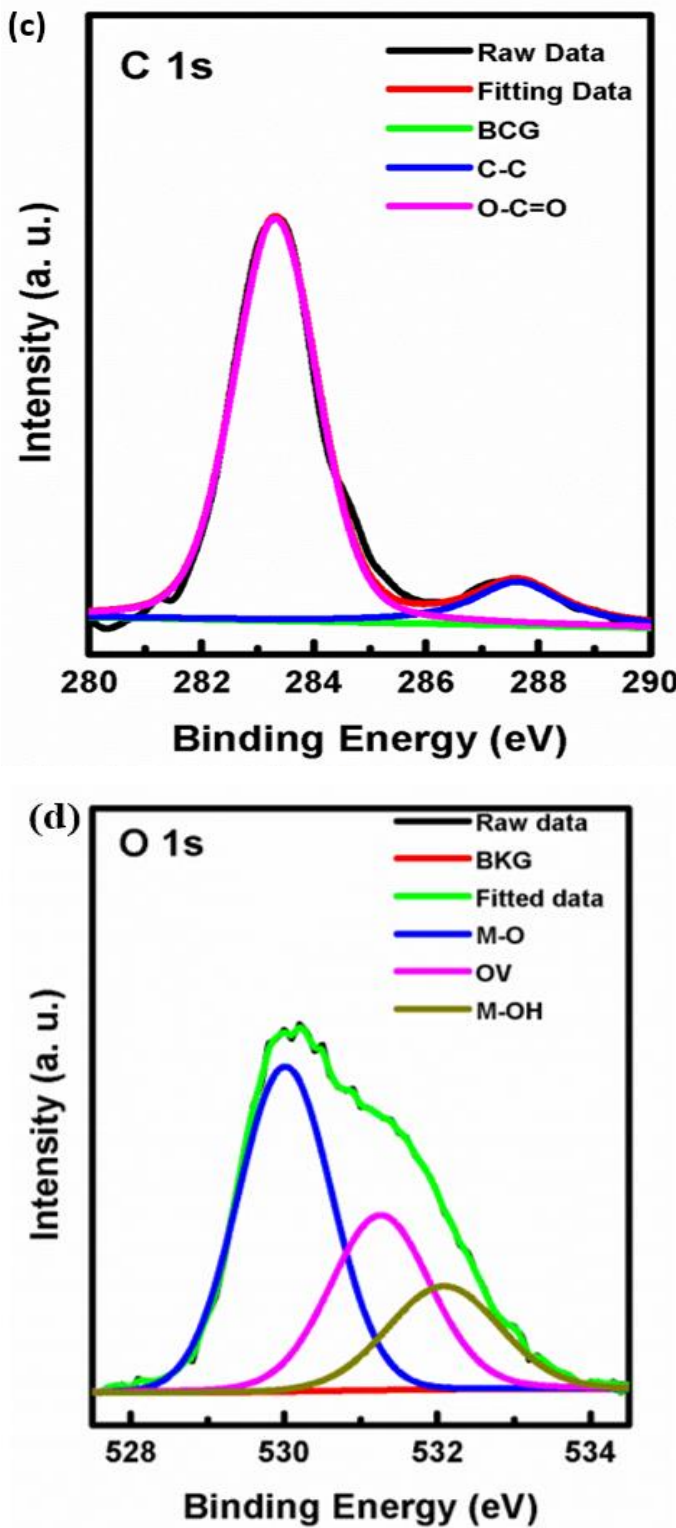
Low Temperature Combustion Processed Stable Al Doped ZnO Thin Film Transistor: Process Extendable up to Flexible Devices
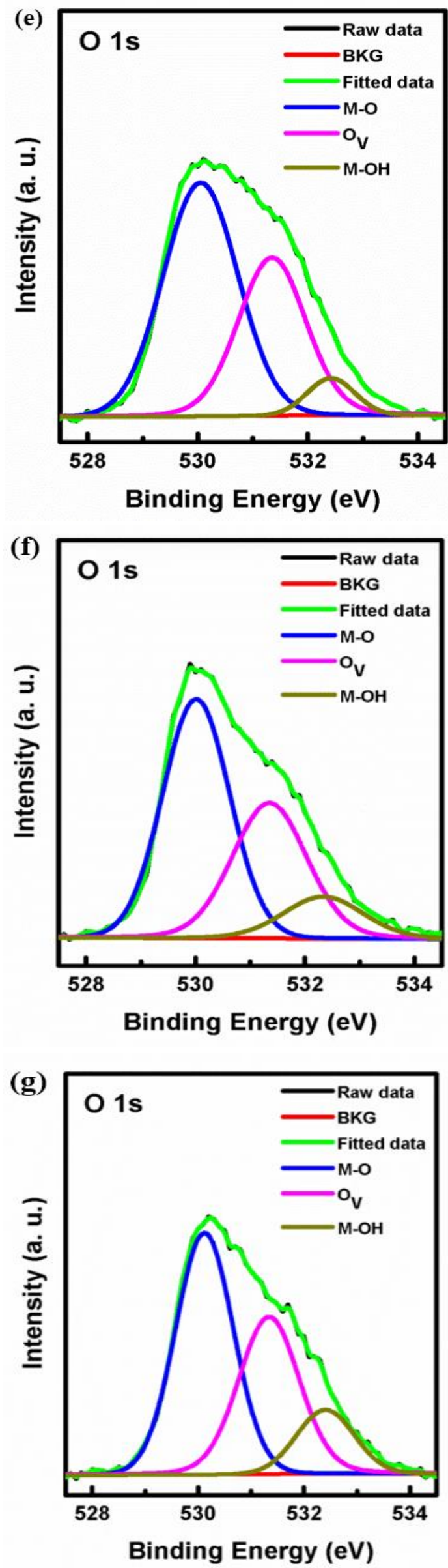

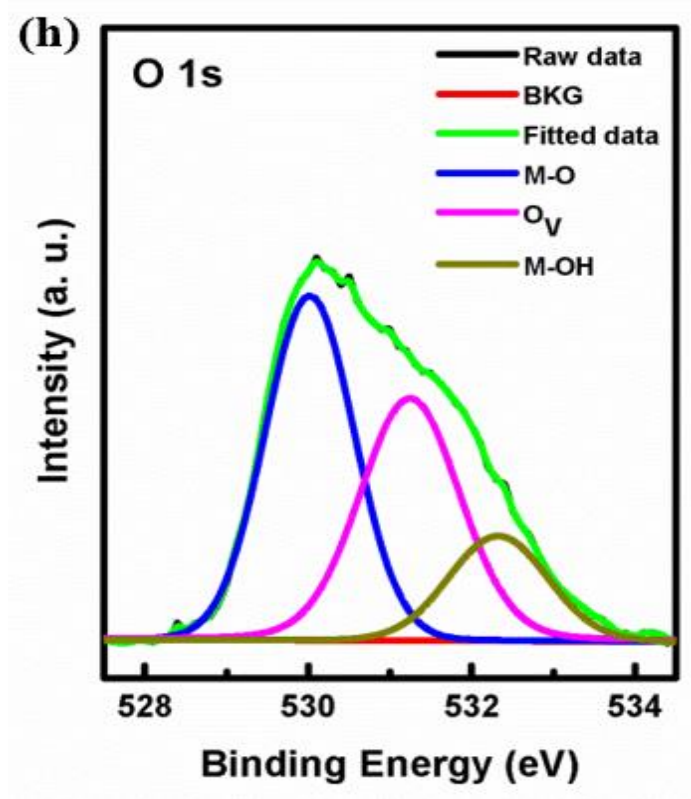

Figure 5: $X P S$ of $A Z O$ thin films of (a) Al $2 p$ of $A Z O$ (7M), (b) Zn $2 p$ of $A Z O$ (7M), (c) $C 1 s$ of $A Z O$ (7M), (d) $O$ 1s of pure $Z n O$, (e) $O$ 1s of $A Z O(3 M)$, (f) $O$ 1s of $A Z O(5 M)$, (g) $O$ 1s of $A Z O(7 M)$ and

(h) $O$ 1s of $A Z O(9 M)$ at $T_{\text {anneal }}=250^{\circ} \mathrm{C}$

A survey scan reveals no organic impurities, in accord with previous combustion studies, and shows slow evolution of the $\mathrm{Zn} 2 \mathrm{p}_{3 / 2}$ and $2 \mathrm{p}_{1 / 2}$ features at $\sim 1020$ and $1043.2 \mathrm{eV}$, respectively, as the amount of $\mathrm{Al} 2 \mathrm{p}$ is increased. Detailed analysis of the oxygen $1 \mathrm{~s}$ spectrum reveals a slight increase in the peak centred at $\sim 288.7 \mathrm{eV}$ as the $\mathrm{Al}$ content is increased. Evaluation of the $\mathrm{O} 1 \mathrm{~s}$ features reveals that as the $\mathrm{Al}$ content is increased, a corresponding decrease in the 530.7 $\mathrm{eV}$ feature occurs, which is ascribable to the metal-oxygen-metal lattice. Concurrently, surface or bulk M-OH species at $532.2 \mathrm{eV}$ increase with increasing $\mathrm{Al}$, in good agreement with the XRD analysis and consistent with our AZO TFT electrical results since it is expected that conduction in AZO channel layer would be due to oxygen vacancies. We expected that the electrical results at the lower annealing temperature would be lower because the formation of defects like oxygen or zinc vacancies requires some activation energy. All the reported films exhibit excellent optical transparency $(>90 \%)$ when deposited on glass. 
Sarangi et al., J. Mod. Mater.; Vol. 3, Issue 1, pp: 14-23, 2017

\subsection{Thin Film Transistors Electrical Characterization}

To investigate electrical performances of as prepared AZO thin film, a TFT was fabricated following bottom gate top contact architecture. Here $\mathrm{SiO}_{2}$ and thermally evaporated $\mathrm{Al}$ were used for gate dielectric and source/drain contacts respectively. A schematic of the device structure of flexible TFTs has been shown in Figure 6.

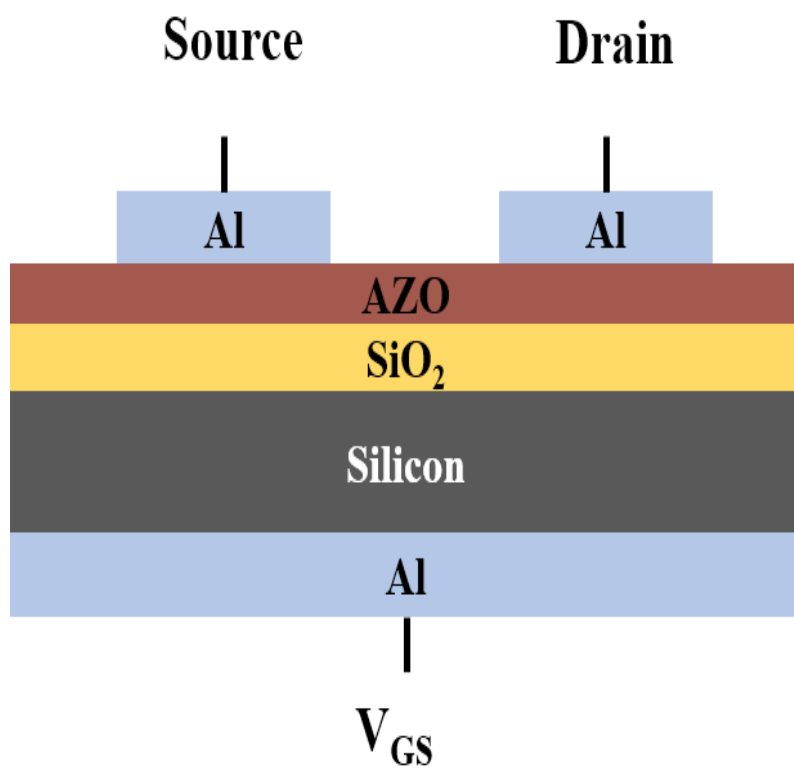

Figure 6: Schematic of the bottom gate AZO Thin film transistor.

\subsubsection{Field Effect Mobility Extraction}

In prevalent method, for crystalline MOSFETs with a grounded source, field-effect mobility is extracted by using the following expression that describes the drain current $\left(\mathrm{I}_{\mathrm{D}}\right)$ is shown in equation 2. [15].

$$
I_{D}=\frac{W}{2 L} \mu_{s a t} C_{o x}\left(V_{G}-V_{T}\right) V_{D}-\frac{V_{D}^{2}}{2}
$$

Where $V_{D}$ is drain-source voltage, $V_{G}$ is (gatesource voltage, $\mu$ is the field-effect mobility, $V_{T}$ is the threshold voltage, and $\mathrm{C}_{\mathrm{ox}}$ is the capacitance per unit area of the gate insulator. In saturation region is $V_{D} \geq V_{G^{-}} V_{T}$. So eqn. 1 can be simplified equation that is shown in equation 3 .

$$
I_{D, s a t}=\frac{W}{2 L} \mu_{s a t} C_{o x}\left(V_{G}-V_{T}\right)^{2}
$$

Field experimental details and $\mathrm{I}_{D}-\mathrm{V}_{\mathrm{G}}$ plots are shows the typical transfer characteristics of AZO TFTs performance metrics that respectively for varied $\mathrm{Al}$ doping concentrations for $\mathrm{T}_{\text {anneal }}=250^{\circ} \mathrm{C}$ are shown in Figure 7 . The device performed excellent properties, such as a high $\mathrm{ON} / \mathrm{OFF}$ ratio of $10^{9}$ at threshold of $15 \mathrm{~V}$, low mobility $\mu_{\mathrm{s}}$ of $0.08 \mathrm{~cm}^{2} / \mathrm{V}$.s for pure ZnO TFT. At lower growth temperatures, a maximum mobility of $1.2 \mathrm{~cm}^{2} \mathrm{~V}^{-1} \mathrm{~s}^{-1}$ is achieved with a large current on/off ratio of $10^{6}$ and a threshold voltage $\left(\mathrm{V}_{\mathrm{T}}\right)$ of $17 \mathrm{~V}$. Notably, as the $\mathrm{Al}$ doping is increased, the mobility decreases significantly, and the devices become inactive at $\geq 7 \mathrm{~mol} \% \mathrm{Al}$. All the calculated AZO TFT mobilities are shown in table 2 .
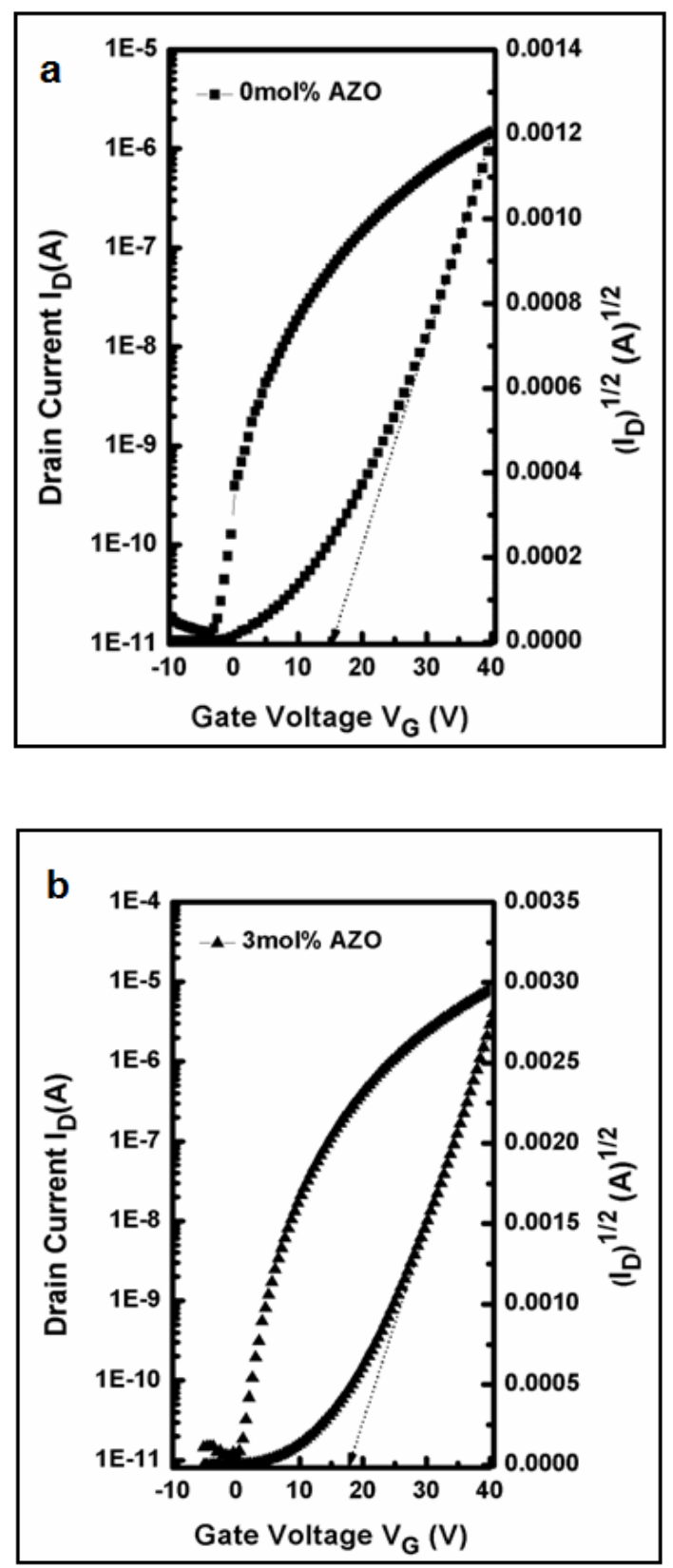

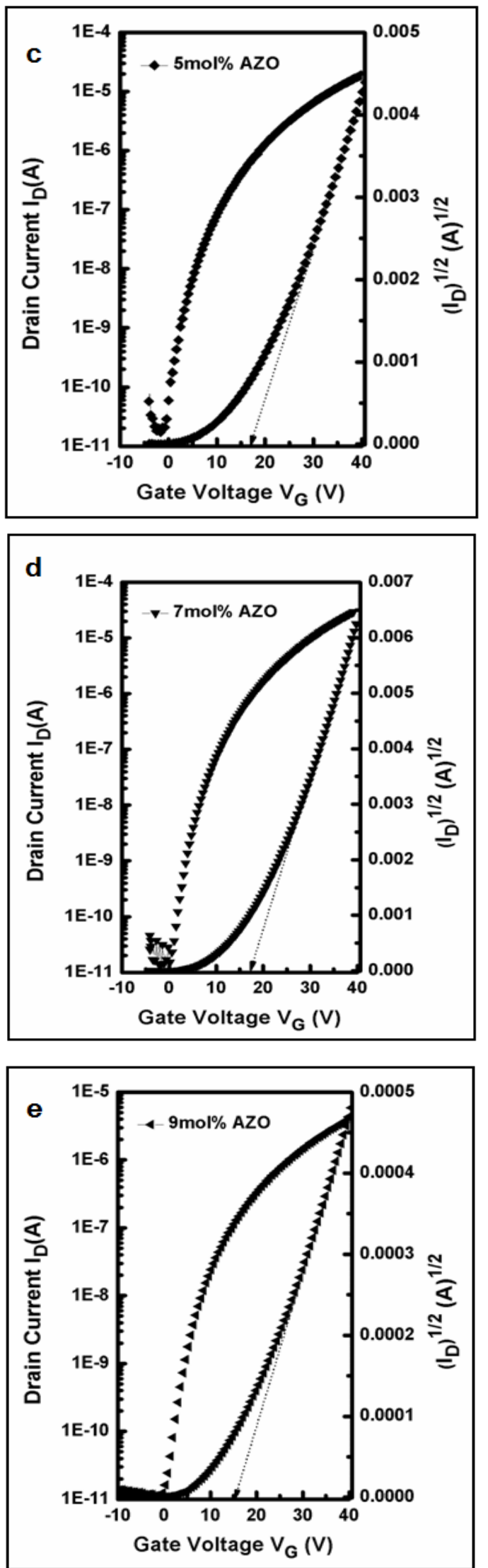

Figure 7: I-V measurement for TFT of different $A l$ dopant molar concentrations (a) $\mathrm{ZnO}$, (b) $\mathrm{AZO}$ with $3 M$, (c) $A Z O$ with $5 M$, (d) $A Z O$ with $7 M$ and
Moreover, as the $\mathrm{Al}$ content is increased from $3 \mathrm{M}$ to $9 \mathrm{M}$, the oxygen vacancy and free carrier concentrations decrease. As a result, $\mathrm{I}_{\mathrm{on}} / \mathrm{I}_{\mathrm{off}}$ initially increases because of the reduced $\mathrm{I}_{\mathrm{off}}$, while a similar $\mathrm{I}_{\text {on }}$ is maintained. Further increases in $\mathrm{Al}$ content depress $\mathrm{I}_{\text {on }} / \mathrm{I}_{\text {off }}$ as a result of the significant decrease in $\mathrm{I}_{\mathrm{on}}$ from the mobility degradation. On the other hand, $\mathrm{V}_{\mathrm{T}}$ is related to the free carrier concentration and trap density. At low $\mathrm{Al}$ content, $\mathrm{V}_{\mathrm{T}}$ follows the trend expected from the decrease in carrier concentration, further confirming the role of oxygen vacancy suppression.

Table 2: IV measurement for AZO TFT of different Al dopant molar concentrations.

\begin{tabular}{|l|l|l|l|l|}
\hline $\begin{array}{c}\text { ZnO } \\
\text { TFT } \\
\text { and } \\
\text { doped } \\
\text { Al }\end{array}$ & $\begin{array}{c}\text { Mobility } \\
\mathbf{c m}^{2} \mathbf{V}^{-1} \mathbf{s}^{-1}\end{array}$ & $\begin{array}{c}\text { Threshold } \\
\text { voltage } \\
\left(\mathbf{V}_{\mathbf{T}}\right)\end{array}$ & $\begin{array}{c}\text { Sub } \\
\text { threshold }\end{array}$ & $\mathbf{I}_{\text {on }} / \mathbf{I}_{\text {off }}$ \\
\hline $\begin{array}{l}\mathrm{ZnO}, \\
\text { 0M }\end{array}$ & 0.08 & 15 & 10.15 & $\sim 10^{6}$ \\
\hline $\begin{array}{l}\mathrm{AZO}, \\
3 \mathrm{M}\end{array}$ & 0.5 & 17 & 7.7 & $\sim 10^{6}$ \\
\hline $\begin{array}{l}\mathrm{AZO}, \\
5 \mathrm{M}\end{array}$ & 0.9 & 16 & 5.2 & $\sim 10^{6}$ \\
\hline $\begin{array}{l}\mathrm{AZO}, \\
7 \mathrm{M}\end{array}$ & 1.2 & 17 & 4.5 & $\sim 10^{6}$ \\
\hline $\begin{array}{l}\mathrm{AZO}, \\
9 \mathrm{M}\end{array}$ & 0.85 & 15 & 6.1 & $\sim 10^{6}$ \\
\hline
\end{tabular}

However, as the $\mathrm{Al}$ content is increased, we observe an unstable trend in $\mathrm{V}_{\mathrm{T}}$. Moreover, when increasing the $\mathrm{Al}$ doping concentration in $\mathrm{ZnO}$ that would be effect on electrons density per unit volume of $\mathrm{AZO}$ to be increased. $\mathrm{AZO}(7 \mathrm{M})$ is optimum one because of this molar concentration provides the moderate electrons to conduct in the channel layers. Where, AZO (9M) or higher concentration is providing the over electrons to conduct in the channel that causes the scattering effect in the electrons cloud and impurities incorporation in substitutional sites would be increased consequently device performance will be poor at higher molar concentration.

(e) AZO with $9 M$. 
Sarangi et al., J. Mod. Mater.; Vol. 3, Issue 1, pp: 14-23, 2017

\subsubsection{Thin-Film Transistor Bias Stress Properties}

To be useful in TFTs, an effective semiconducting channel material must be stable under constant bias stress [19]. Previous reports have shown that metal oxide semiconductor performance under bias stress is related to a variety of factors, including $\mathrm{H}_{2} \mathrm{O}$ and $\mathrm{O}_{2}$ adsorption on the back channel and electron trapping at the semiconductor/dielectric interface. Thin semiconductor films (as in the present case), $\mathrm{H}_{2} \mathrm{O}$ adsorption has been shown to create an accumulation layer due to electron donation, resulting in a negative $V_{T}$ shift. On the other hand, $\mathrm{O}_{2}$ adsorption is known to form a depletion layer below the active surface, leading to a positive $\mathrm{V}_{\mathrm{T}}$ shift. Unlike trapping at the semiconductor/dielectric interface, these two factors can be mitigated by appropriate passivation of the channel. Measured the properties of the AZO channel materials, TFTs were fabricated as described previously (here channel $\mathrm{L}=200, \mathrm{~W}=300 \mu \mathrm{m}$ ) with $7 \mathrm{M}$ concentration of $\mathrm{Al}$ was the better performance of the device and $\mathrm{T}_{\text {anneal }}=250{ }^{\circ} \mathrm{C}$. These devices were then subjected to a $V_{G}-V_{D}$ constant bias of $+10 \mathrm{~V}$ for $100 \mathrm{~s}$ intervals for the duration of 1000 $s$ in ambient, with intentional light blocking. The resulting transfer plots are shown in Figure 8.

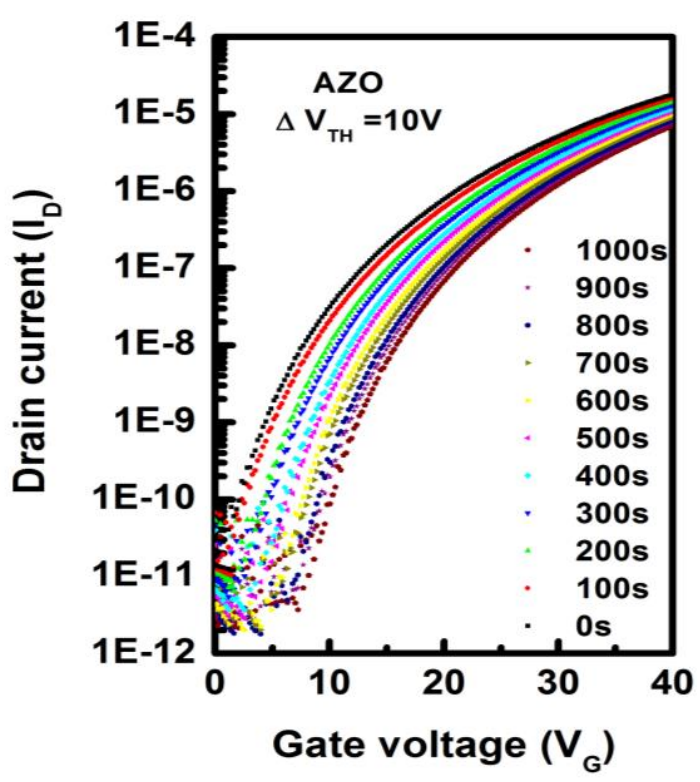

Figure 8: Effect of the gate bias stress on the transfer characteristics for AZO TFTs with Al dopant of $7 \mathrm{M}$ and $T_{\text {anneal }}=250^{\circ} \mathrm{C}$. Gate-to-drain bias $+10 \mathrm{~V}$ was maintained for $100 \mathrm{~s}$ between transfer measurements for $1000 \mathrm{~s}$.
As expected, the direction of bias related shifts are toward positive voltages as indicated by the black arrow in the top left pane. This positive shift is expected from previous studies which argued that under positive bias stress a AZO forms oxygen-related electron-trapping (acceptor-like) states. All four AZO TFT classes exhibit a fall in $\mathrm{I}_{\text {off }}$ over the bias duration, although the fall is significantly more limited in the case of AZO devices. The threshold voltage for each system lies within the typical range observed for AZO TFTs investigated in this study. In general, the best-performing TFTs having films prepared with each oxygen getter at both film processing temperatures exhibit $V_{T}$ 's in the range of 0 to $10 \mathrm{~V}$, with a positive shift observed with increasing $\mathrm{Al}$ concentration up to 7M.

\section{Conclusions}

We demonstrated, combustion synthesis of polycrystalline Aluminium doped zinc oxide (AZO) thin film transistors at low annealing temperatures of $250{ }^{\circ} \mathrm{C}$ with a maximum field effect mobility value of $1.2 \mathrm{~cm}^{2} \mathrm{~V}^{-1} \mathrm{~s}^{-1}$ and threshold voltage of $17 \mathrm{~V}$ at $7 \mathrm{~mol}$. \% of $\mathrm{Al}$ doping. Devices without $\mathrm{Al}$ doping demonstrated field effect mobility of $0.08 \mathrm{~cm}^{2} \mathrm{~V}^{-1} \mathrm{~s}^{-1}$ and $15 \mathrm{~V}$, respectively. Based on the obtained results, it is confirmed that $\mathrm{Al}$ act as a very effective dopant for enhancing the electrical performance at 250 ${ }^{\circ} \mathrm{C}$ and device stability of $\mathrm{ZnO}$ based TFTs by increasing charge carrier concentration and reducing the number of scattering centres. Thus, combustion synthesis of polycrystalline Aluminium doped zinc oxide (AZO) thin film transistors may enable several low cost flexible electronic applications.

\section{Acknowledgment}

The authors would like to thank Center for Excellence in Nanoelectronics (CEN), Sophisticated Analytical Instrument Facility (SAIF), Department of Metallurgical Engineering and Materials Science (MEMS) at Indian Institute of Technology Bombay (IIT Bombay) Mumbai, India, for providing various facilities for device fabrication and characterization. 


\section{How to Cite this Article:}

V. Sarangi and S. Gandla, "Low Temperature Combustion Processed Stable Al Doped ZnO Thin Film Transistor: Process Extendable up to Flexible Devices", J. Mod. Mater., vol. 3, no. 1, pp. 14-23, Dec. 2016. doi: 10.21467/jmm.3.1.14-23

\section{References}

[1] L. Lan, P. Xiao, M. Li, H. Xu, R. Yao, S. Wen, and J. Peng, "Enhancement of bias and illumination stability in thin-film transistors by doping $\mathrm{InZnO}$ with wide-bandgap Ta2O5," Appl. Phys. Lett., vol. 102, no. 24, p. 242102, 2013.

[2] S. Stankovich, D. A. Dikin, G. H. B. Dommett, K. M. Kohlhaas, E. J. Zimney, E. A. Stach, R. D. Piner, S. T. Nguyen, and R. S. Ruoff, "Graphene-based composite materials.," Nature, vol. 442 , no. 7100 , pp. $282-286$, 2006. View

[3] C. Li, Y. Li, Y. Wu, B. Ong, and R. Loutfy, "Fabrication conditions for solution-processed high-mobility $\mathrm{ZnO}$ thin-film transistors," J. Mater. Chem., vol. 19, pp. 162616341634, 2009.

[4] X. Xu, L. Feng, S. He, Y. Jin, and X. Guo, "Solutionprocessed zinc oxide thin-film transistors with a lowtemperature polymer passivation layer," IEEE Electron Device Lett., vol. 33, no. 10, pp. 1420-1422, 2012.

[5] P. F. Carcia, R. S. McLean, and M. H. Reilly, "Highperformance $\mathrm{ZnO}$ thin-film transistors on gate dielectrics grown by atomic layer deposition," Appl. Phys. Lett., vol. 88, no. 2006, pp. 10-13, 2006.

[6] J. H. Jun, B. Park, K. Cho, and S. Kim, "Flexible TFTs based on solution-processed $\mathrm{ZnO}$ nanoparticles.," Nanotechnology, vol. 20, p. 505201, 2009.

[7] S. Y. Park, B. J. Kim, K. Kim, M. S. Kang, K. H. Lim, T. Il Lee, J. M. Myoung, H. K. Baik, J. H. Cho, and Y. S. Kim, "Low-temperature, solution-processed and alkali metal doped zno for high-performance thin-film transistors," Adv. Mater., vol. 24, pp. 834-838, 2012.

[8] K. K. Banger, Y. Yamashita, K. Mori, R. L. Peterson, T. Leedham, J. Rickard, and H. Sirringhaus, "Lowtemperature, high-performance solution-processed metal oxide thin-film transistors formed by a 'sol-gel on chip' process.," Nat. Mater., vol. 10, no. 1, pp. 45-50, 2011.

[9] Y. H. Kang, S. Jeong, J. M. Ko, J.-Y. Lee, Y. Choi, C. Lee, and S. Y. Cho, "Two-component solution processing of oxide semiconductors for thin-film transistors via self-combustion reaction," J. Mater. Chem. C, vol. 2, no. 21, pp. 4247-4256, 2014.

[10] H. Wang, T. Sun, W. Xu, F. Xie, L. Ye, Y. Xiao, Y. Wang, J. Chen, and J. Xu, "RSC Advances dielectric for combustion derived oxide thin fi lm," RSC Adv., vol. 4, no. 3, pp. 54729-54739, 2014.

[11] Hennek, Jonathan W., Jeremy Smith, Aiming Yan, Myung-Gil Kim, Wei Zhao, Vinayak P. Dravid, Antonio Facchetti, and Tobin J. Marks, "Oxygen "getter" effects on microstructure and carrier transport in low temperature combustion-processed a-InXZnO $(\mathrm{X}=\mathrm{Ga}$, Sc, Y, La) transistors." J. Am. Chem. Soc, 135, no. 29, pp. 10729-10741, 2013.

[12] S. Jeong and J. Moon, "Low-temperature, solutionprocessed metal oxide thin film transistors," J. Mater. Chem., vol. 22, pp.1243-1250, 2012.

[13] M.-G. Kim, M. G. Kanatzidis, A. Facchetti, and T. J. Marks, "Low-temperature fabrication of highperformance metal oxide thin-film electronics via combustion processing.," Nat. Mater., vol. 10, no. 5, pp. 382-388, 2011.

[14] L. Lu, M. Echizen, T. Nishida, Y. Ishikawa, K. Uchiyama, and Y. Uraoka, "Low-temperature fabrication of solution-processed $\mathrm{InZnO}$ thin-film transistors with $\mathrm{Si}$ impurities by UV/O3-assisted annealing," AIP Adv., vol. 2, no. 3, p. 032111, 2012.

[15] W. H. Lee, J. Park, S. H. Sim, S. B. Jo, K. S. Kim, B. H. Hong, and K. Cho, "Transparent flexible organic transistors based on monolayer graphene electrodes on plastic," Adv. Mater., vol. 23, no. 15, pp. 1752-1756, 2011.

[16] Y. Cao, M. L. Steigerwald, C. Nuckolls, and X. Guo, "Current trends in shrinking the channel length of organic transistors down to the nanoscale," Adv. Mater., vol. 22, no. 1, pp. 20-32, 2010.

[17] J. Cai, D. Han, Y. Geng, W. Wang, L. Wang, S. Zhang, and Y. Wang, "High-performance transparent AZO TFTs fabricated on glass substrate," IEEE Trans. Electron Devices, vol. 60, no. 7, pp. 2432-2435, 2013.

[18] W. Wang, D. H. Ã, J. Cai, Y. Geng, L. Wang, and L. Wang, "Fully Transparent Al-Doped $\mathrm{ZnO}$ Thin-Film Transistors on Flexible Plastic Substrates Fully Transparent Al-Doped ZnO Thin-Film Transistors on Flexible Plastic Substrates," Japanese Journal of Applied Physics vol. 10, no.4S, pp. 2-5, 2013.

[19] A. Suresh and J. F. Muth, "Bias stress stability of indium gallium zinc oxide channel based transparent thin film transistors,” Appl. Phys. Lett., vol. 92, no. 2008, 2008.

Publish your research article in AIJR journals-

$\checkmark$ Online Submission and Tracking

$\checkmark$ Peer-Reviewed

$\checkmark$ Rapid decision

$\checkmark \quad$ Immediate Publication after acceptance

$\checkmark$ Articles freely available online

$\checkmark \quad$ Retain full copyright of your article.

Submit your article at journals.aijr.in

Publish your books with AIJR publisher-

$\checkmark \quad$ Publish with ISBN and DOI.

$\checkmark$ Publish Thesis/Dissertation as Monograph.

$\checkmark$ Publish Book Monograph.

$\checkmark$ Publish Edited Volume/ Book.

$\checkmark$ Publish Conference Proceedings

$\checkmark \quad$ Retain full copyright of your books.

Submit your manuscript at books.aijr.org 